\title{
Chapter 4 \\ Environmental Contamination \\ and Decontamination After Fukushima \\ Daiichi Accident
}

\author{
Joonhong Ahn
}

\begin{abstract}
In this chapter, effectiveness of the environmental decontamination is discussed from the point of view of waste management. First, the relation between the environmental contamination and the radiation dose rate to the resident is summarized. Then, a model has been developed to understand effectiveness of artificial decontamination measures to achieve the goals set by the Japanese law. The analysis revealed the importance of waste volume reduction by strategic selection of areas for decontamination and development of volume reduction technologies. Decontamination can effectively contribute to reduction of the air dose rate if it is applied in areas where natural dispersion is slow, and thus strategic prioritization of areas for decontamination is highly recommended. Because of high heterogeneity of the natural environment, an adaptive, staged approach with feedbacks from actual decontamination should be taken. Instead of constructive feedback loop, however, we observe a vicious cycle consisting of a lack of integrated scientific knowledge base about environmental contamination and deterioration in trust among stakeholders in society. To halt this vicious cycle, we need to establish a fundamental scientific basis, both natural and social, for enabling in-depth analysis about what has been the most crucial damage resulting from the accident and why that occurred, and how radiological risk can or should be compared with other risks in society.
\end{abstract}

Keywords Decontamination $\cdot$ Natural dispersion $\cdot$ Cost $\cdot$ Feedback from stakeholders

\footnotetext{
J. Ahn ( $\square)$

Department of Nuclear Engineering, University of California, Berkeley,

Berkeley, CA 94720, USA

e-mail: joonhong.ahn@ berkeley.edu
} 


\subsection{Prologue}

On September 11, 2012, 18 months after the Great East Japan Earthquake and tsunami hit Japan, I visited the towns of Kawamata, Namie, Okuma, and MinamiSoma in Fukushima Prefecture. It was a bright, sunny day.

Ever since the accident, I had been feeling that I must visit the scene of the accident and see for myself what had happened. At the same time, I did not want to create more work for those who bore the heavy responsibility of dealing with its aftermath. After some vacillation, I gingerly asked Dr. Shinichi Nakayama, a close friend of mine, if I could have an opportunity to observe the restricted areas. Before the accident, he had worked for many years at the Japan Atomic Energy Agency (JAEA) on basic research in the geochemistry of radionuclides. After the accident, JAEA established an office in Fukushima to give scientific advice on environmental decontamination to the Prefectural government and local communities. Dr. Nakayama was then the deputy head of this new office. He willingly agreed to my request, saying that he had already welcomed such visitors several times, including those from overseas, and arranged a 1-day tour for me with six other researchers from JAEA (Fig. 4.1). The inside of our car was fully covered with plastic sheeting to protect the vehicle from being contaminated by dirt tracked in on our shoes. Each of us had a pocket dosimeter.

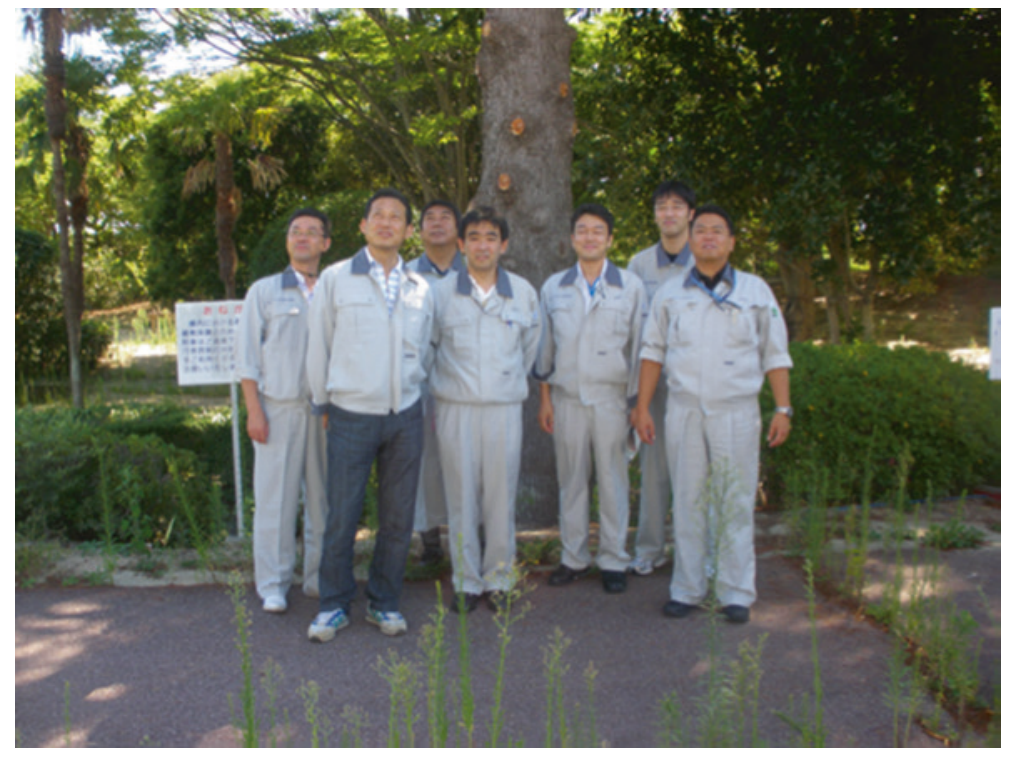

Fig. 4.1 Researchers of JAEA Fukushima, who accompanied me during the 1-day tour, taken in front of Okuma Town Hall on September 11, 2012. Dr. Nakayama is second from left 


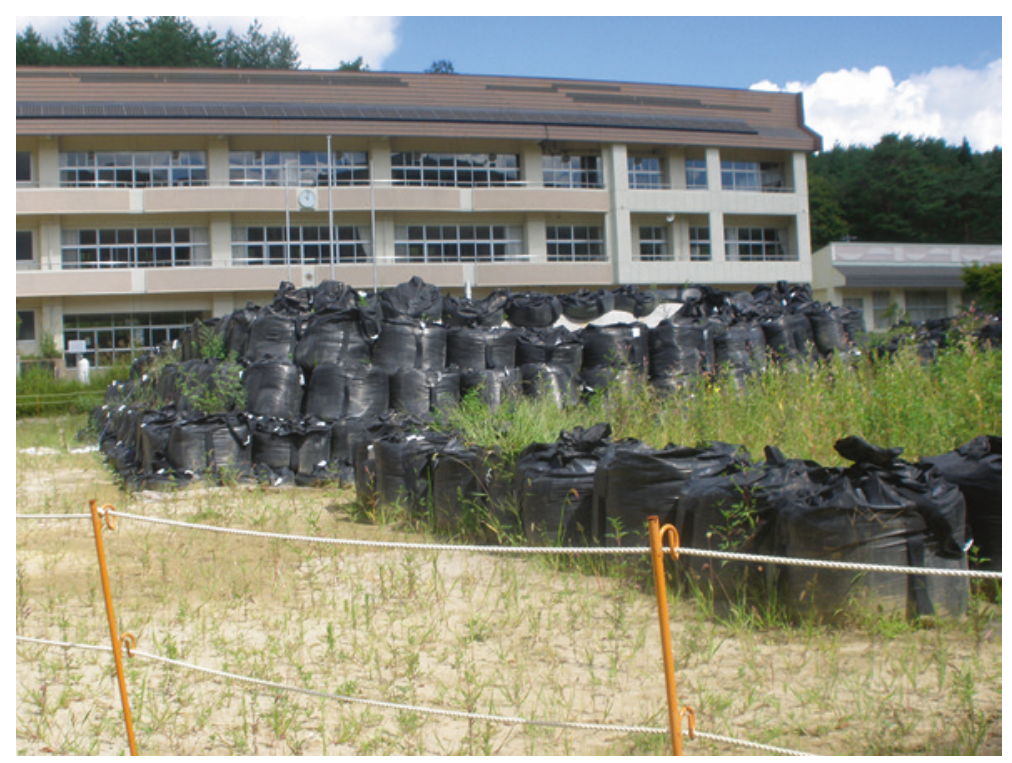

Fig. 4.2 Plastic bags containing waste from decontamination, or josen, piled up in the schoolyard in the Town of Namie, Fukushima Prefecture; taken on September 11, 2012

I was nearly speechless during the day. The mountains, forests, fields, farms, school buildings, playgrounds and houses looked peaceful and intact, though unnaturally quiet (Fig. 4.2). Police cars often passed by, breaking the silence. They were patrolling empty houses to protect them from theft by intruders. Then, we stepped into the coastal area in the town of Okuma, which was inundated by the tsunami. Because the area was within a mile of the Fukushima Daiichi Nuclear Power Station and the radiation level was high, it had been left untouched since the accident. All that was displayed in front of my eyes was emptiness covered by dense summer grasses.

This view was completely different from what I had seen in Kobe in February 1995, a month after the Great Hanshin-Awaji Earthquake, when I went there to visit my late brother and his family. In Kobe I saw many heavily destroyed buildings and roads, and through my brother's work [1] as a psychiatrist, the difficulties and agony of survivors. But in Fukushima, it took me some time to comprehend those scenes of silence and disappearance, although they continued to gnaw on my mind long after. That night I had a late supper by myself after parting from the JAEA researchers, profoundly unsettled by the emptiness I had witnessed.

The full impact of the Fukushima nuclear disaster on Japanese society goes far beyond matters directly related to what happened within the nuclear power plant itself. From among dozens of critical issues that should be taken up, I have limited my focus in this chapter to decontamination of the environment and its consequences from the point of view of waste management. 


\subsection{Environmental Contamination}

We first need to grasp the degree and nature of contamination of the environment due to the release of radioactive materials from the Fukushima Daiichi site, which could cause people to receive radiation doses (potential health hazard) through various pathways. Readers are referred to Chap. 3 , which gives in-depth analysis about the sources of environmental contamination.

\subsubsection{Surface Radioactivity Concentrations}

\subsubsection{Areal Extension of Contamination}

The map (Fig. 4.3) shows the parts of Japan that were affected by radioactive fallout from the Fukushima Daiichi Nuclear Power Station. More precisely stated, Fig. 4.3 shows where and to what extent the land has been contaminated by two isotopes ${ }^{1}$ of cesium (Cs), Cs-134 and Cs-137. Eight prefectures are shaded in brown, from Yamagata and Miyagi prefectures at the top, Fukushima Prefecture directly below them, followed by Gunma, Tochigi, Ibaraki, and Saitama, and then Chiba at the very bottom. The Tokyo metropolis is nestled at the junction of the southeastern border of Saitama and the northwestern border of Chiba.

\subsubsection{Radionuclides of Concern}

Any consideration of decontamination options must begin with a basic understanding of the properties of the radioactive isotopes involved. As Chap. 3 discusses, during the 1st week of the accident, iodine isotopes (mostly iodine-131, with a half-life of 8 days) were released and dispersed into the environment, and then diminished fairly soon through a process of spontaneous radioactive decay. Cs-134 and Cs-137 were also released from the damaged reactors and widely dispersed into the environment, settling on the surfaces of soil, trees, water, roads, and buildings. But unlike iodine contamination, which had diminished before it was measured, the level of cesium contamination, still present owing to their much longer half-lives, can be measured and expressed by radioactivity, as the number of becquerels (Bq), per square meter of surface (Fig. 4.3).

\footnotetext{
${ }^{1}$ Isotopes are variants of a particular chemical element. While all isotopes of a given element have the same number of protons in each atom, they differ in neutron number. All cesium isotopes have 55 protons.
} 


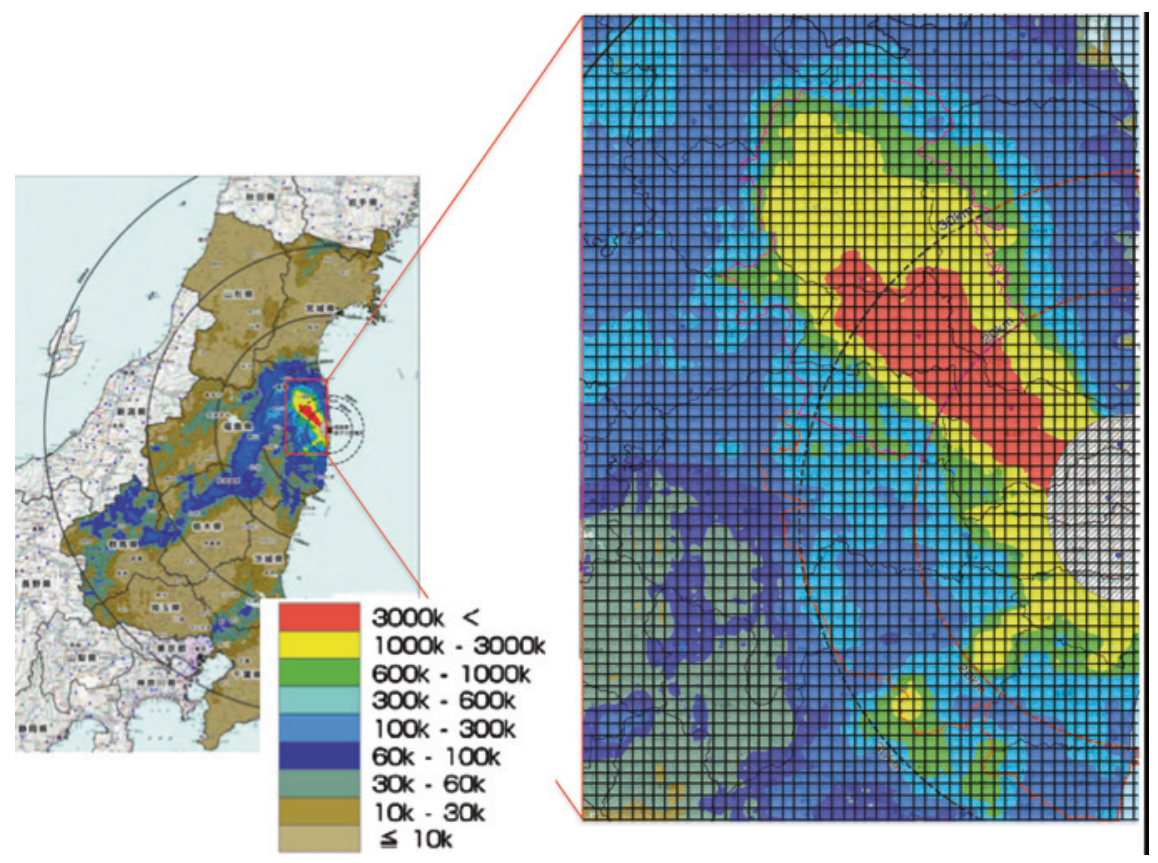

Fig. 4.3 Surface radioactivity concentrations of Cs-134 and Cs-137 as of September 18, 2011 [2]. The right figure is an enlargement of the most contaminated area. The grid lines overlapped on the map are drawn $1 \mathrm{~km}$ apart. Thus, one small rectangle covers an area of $1 \mathrm{~km}^{2}$

\subsubsection{Radioactivity Concentrations}

The radioactivity of a radioisotope is proportional to its mass. For example, $1 \mathrm{~g}$ of the radioisotope Cs-134 is equivalent to $1(\mathrm{~g}) / 134(\mathrm{~g} / \mathrm{mol})=0.00746 \mathrm{~mol}^{2}$ Because $1 \mathrm{~mol}$ includes the Avogadro number, $6.02 \times 10^{23}$, of atoms, $1 \mathrm{~g}$ of Cs-134 includes $4.5 \times 10^{21}$ atoms. The second step in calculating becquerel is that it is known that an atom decays with a certain probability in unit time. This probability is expressed by the decay constant, usually denoted with the symbol "lambda" (the eleventh letter of the Greek alphabet) $\lambda$ (1/s). For Cs-134, lambda $(\lambda)$ is known to be $1.06 \times 10^{-8}(1 / \mathrm{s})$. The radioactivity of $1 \mathrm{~g}$ of $\mathrm{Cs}-134$ can then be calculated as $4.5 \times 10^{21}$ (i.e. the total number of atoms) $\times 1.06 \times 10^{-8}$ (i.e. the rate of decay per unit time $)=4.8 \times 10^{13}$ atoms decayed per second, or 48 trillion becquerels.

\footnotetext{
2 According to International Bureau of Weights and Measures (IBWM), the mole is defined to be the amount of substance of a system which contains as many elementary entities (e.g. atoms, molecules, ions, electrons) as there are atoms in $0.012 \mathrm{~kg}$ of carbon- $12\left({ }^{12} \mathrm{C}\right)$, the isotope of carbon with relative atomic mass 12 . Thus, by definition, one mole of pure ${ }^{12} \mathrm{C}$ has a mass of exactly $12 \mathrm{~g}$.
} 
Let us now return to Fig. 4.3. The surface concentration is shown in units of $\mathrm{Bq} / \mathrm{m}^{2}$, or the number of atoms decayed per second per square meter. For example, the red-colored region is contaminated at a concentration of " $3,000 \mathrm{kBq} / \mathrm{m}^{2}$ or greater," which means more than 3 million becquerels per square meter. As will be explained later (also shown in Chap. 3 of this volume), half of this contamination is due to Cs-134. So if the surface concentration at a location of interest is 3 million becquerels per square meter $\left(\mathrm{Bq} / \mathrm{m}^{2}\right)$, then 1.5 million becquerels of Cs-134 exists per square meter at that location. To express this level of contamination in terms of mass (grams) rather than radioactivity (becquerels), we can divide the number of becquerels just calculated (1.5 million per square meter) by the number of atoms decayed per second, as calculated in the preceding paragraph $\left(4.8 \times 10^{13}\right)$, as follows: $1.5 \times 10^{6} / 4.8 \times 10^{13}=0.031 \times 10^{-6} \mathrm{~g} / \mathrm{m}^{2}$, or $0.031 \mu \mathrm{g} /$ $\mathrm{m}^{2}$. In other words, in Fig. 4.3, the Cs-134 contamination of the red-colored region is about three-hundredths of a microgram of Cs-134 spread over the area of $1 \mathrm{~m}^{2}$.

\subsubsection{Radiation Doses Due to Contamination}

\subsubsection{Sievert}

Besides becquerels and grams, there is one other unit of measurement-sievertthat we must understand in order to comprehend effects of radiation on human bodies resulting from radioactive contamination such as the data presented in Fig. 4.3. When nuclei decay, they emit energized particle(s), such as electrons, neutrons, protons, photons, and helium nuclei. These particles lose their energy while in motion whenever they interact with and transfer kinetic energy to other matter that exists along their trajectory, such as air, concrete, paper, water, and human tissue. When an energized particle hits a human body, it transfers its energy to human tissue, and in some cases causes irrecoverable damage (see Chap. 13). The severity of damage is dependent on the energy and type of particle, and on part of the body hit by the particle. While the first two factors are physical, the third is biological. Sievert $(\mathrm{Sv})$ is a unit of measurement for a radiation dose that takes into account these three factors. Sievert expresses the combined effects (i.e., severity) of emitted energetic particles on a human body.

\subsubsection{Pathways that Cause Radiation Dose}

To estimate how much radiation dose $(\mathrm{Sv})$ would be caused by the observed contamination of Cs-134 and Cs-137 in the environment, various pathways need to be taken into account. A report [3] published by the International Atomic Energy Agency (IAEA) shows a generic model for radiation dose evaluation. 


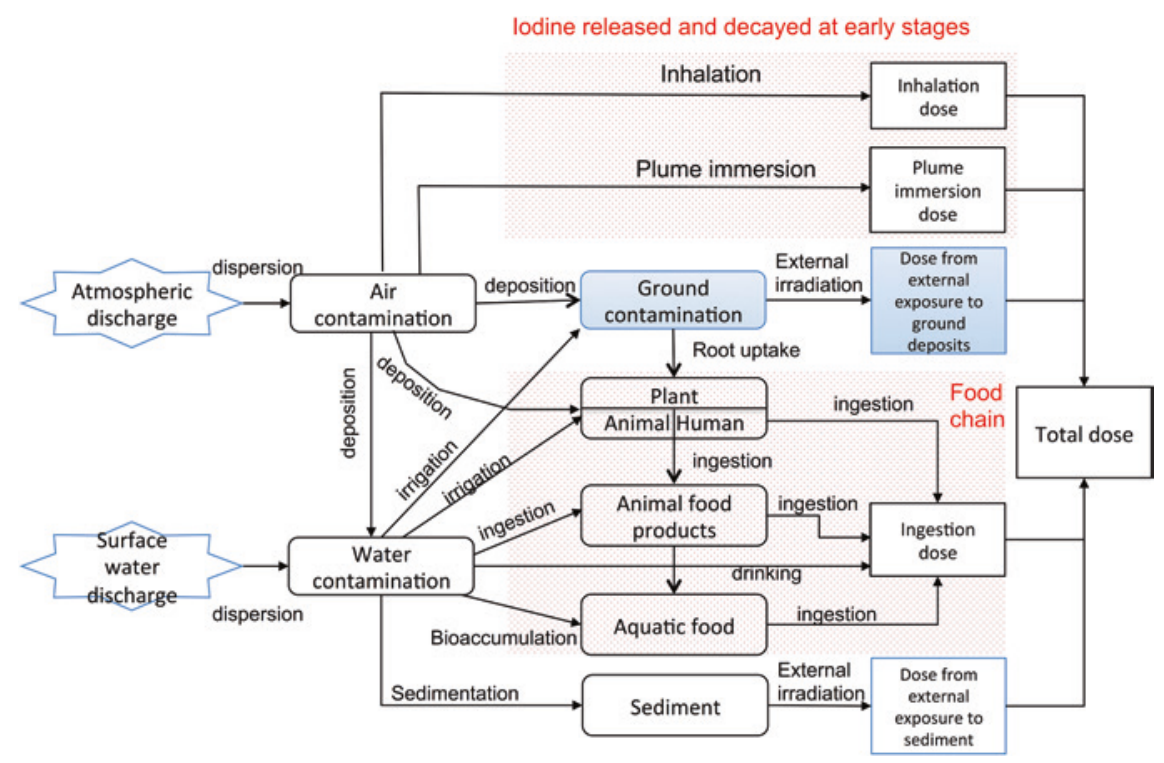

Fig. 4.4 Generic models for assessing the impact of discharges of radioactive substances to the environment [3]

Figure 4.4 depicts multiple pathways that affect radiation dose to a resident in a contaminated area. The box labeled as "Total dose" at the right of Fig. 4.4 indicates that the total dose results from various causes, such as inhalation of radionuclides floating in the atmosphere, external radiation due to immersion in the radionuclide plume in the atmosphere, external radiation exposure to radionuclides deposited on the ground surface, ingestion of foodstuffs contaminated by radionuclides, etc.

Among those, the first two pathways, i.e., inhalation and plume immersion, occurred within a few weeks after the initial accident. Due to failure in conducting systematic measurement at the early stage of the accident, however, only an indirect way is now possible for dose evaluation for these pathways. ${ }^{3}$ The ingestion pathway through contaminated foodstuffs can be avoided by applying stringent inspection for foodstuffs before they enter the commercial market. Thus, in this analysis, we focus on the external radiation due to exposure to radionuclides deposited on the ground surface.

\footnotetext{
${ }^{3}$ In such indirect estimates, first, evolution of radioactivity plumes with time is simulated by utilizing detailed information on the source term, i.e., how much radioactivity was released from the Fukushima Daiichi site, and on the meteorological data. Then, information on traces of people's movements during the first few weeks needs to be collected. Finally, the radiation dose can be estimated for individual evacuees.
} 


\subsubsection{Hourly Dose}

For radiation due to exposure to radionuclides deposited on the ground surface, the relation between the surface concentration and the hourly radiation dose to a resident is given in the IAEA report by the conversion factor $2.1 \times 10^{-3}(\mu \mathrm{Sv} / \mathrm{h}) /(\mathrm{kBq} /$ $\mathrm{m}^{2}$ ) for Cs-137, and the factor $5.6 \times 10^{-3}(\mu \mathrm{Sv} / \mathrm{h}) /\left(\mathrm{kBq} / \mathrm{m}^{2}\right)$ for Cs-134. A study in Fukushima [4] indicates that the radioactivity of Cs-137 and Cs-134 observed in the environment was approximately the same soon after the accident. Therefore, for example, at a location with contamination of $1,000 \mathrm{kBq} / \mathrm{m}^{2}, 500 \mathrm{kBq} / \mathrm{m}^{2}$ is due to $\mathrm{Cs}-137$ and $500 \mathrm{kBq} / \mathrm{m}^{2}$ is due to Cs-134. Using these values, we can calculate the total hourly radiation dose to a resident located at a point with $1,000 \mathrm{kBq} / \mathrm{m}^{2}$ of contamination in the following way: $2.1 \times 10^{-3}(\mu \mathrm{Sv} / \mathrm{h}) /\left(\mathrm{kBq} / \mathrm{m}^{2}\right) \times 500(\mathrm{kBq} /$ $\left.\mathrm{m}^{2}\right)+5.6 \times 10^{-3}(\mu \mathrm{Sv} / \mathrm{h}) /\left(\mathrm{kBq} / \mathrm{m}^{2}\right) \times 500\left(\mathrm{kBq} / \mathrm{m}^{2}\right)=3.8 \mu \mathrm{Sv} / \mathrm{h}$. This means that if you stay at a location contaminated by these two cesium isotopes with a total concentration of $1,000 \mathrm{kBq} / \mathrm{m}^{2}$, then you will get $3.8 \mu \mathrm{Sv}$ of radiation dose every hour. It should be noted that $2.8 \mu \mathrm{Sv} / \mathrm{h}$ is contributed by Cs-134 because of the greater conversion factor. With the shorter half-life for Cs-134, this contribution decreases faster than that by Cs-137.

\subsubsection{Annual Dose}

The guidelines of the decontamination measures announced by the government are expressed in terms of the annual dose, as shown in the next section. To obtain the conversion relation between the annual dose and the hourly dose, we need to make assumptions about people's daily life and living conditions. Suppose that (1) a person stays outside of buildings for $8 \mathrm{~h}$ and inside for $16 \mathrm{~h}$ a day, and (2) while inside, because of shielding effects by the building's walls, the radiation dose is reduced to $40 \%$ of that observed outside. In such a scenario, $3.8 \mu \mathrm{Sv} / \mathrm{h}$ for example can be converted as follows: $[3.8(\mu \mathrm{Sv} / \mathrm{h}) \times 8$ (hours-outside/day) $+3.8 \times 0.4$ $(\mu \mathrm{Sv} / \mathrm{h}) \times 16$ (hours-inside/day) $] \times 365$ (days/year) $=20,000 \mu \mathrm{Sv} /$ year or $20 \mathrm{mSv} / \mathrm{year}^{4}{ }^{\mathrm{In}}$ this manner, the surface radioactivity concentration of Cs-134 and $\mathrm{Cs}-137$ can be related to an annual dose of radiation.

\subsubsection{Regulatory Guidelines}

The Japanese government enacted a law on special measures on August 30, 2011 [5]. It stated that (1) the annual dose is to be made less than $20 \mathrm{mSv} / \mathrm{year}$ within 2 years, and (2) $1 \mathrm{mSv} / \mathrm{year}$ or lower at any location in the long term.

Returning again to Fig. 4.3, the surface concentrations of cesium in the yellow and red regions exceed the $1,000 \mathrm{kBq} / \mathrm{m}^{2}$ level, in which case, as the calculation

${ }^{4} 1 \mathrm{mSv}$ (milli sievert) is equal to $1,000 \mu \mathrm{Sv}$. 
above illustrates, annual doses exceed the $20 \mathrm{mSv} / \mathrm{year}$ level. This fact indicates that efforts to reduce the surface concentration of cesium should be focused in these regions to achieve the first guideline. To achieve the second guideline requires decontamination of a much broader area. With the proportionality between the surface concentration and the annual dose, the target area of decontamination would be all places with a surface contamination greater than $50 \mathrm{kBq} /$ $\mathrm{m}^{2}$, in other words the areas corresponding to the first through the seventh bars in the legend for Fig. 4.3.

\subsection{Modeling of Decontamination to Help Decision Making}

\subsubsection{Purpose of Modeling}

With the two decontamination guidelines defined by the law, more practical and burning questions arise immediately as to how soon these goals can actually be achieved, how much it will cost, and what the parameters are that could significantly affect effectiveness of a decontamination job. In the 3 years since the accident, a tremendous amount of effort has already been devoted to decontamination, but little information was shared in the public domain, which is what enables Japanese citizens to have informed discussions for determining national and local policies and procedures for decontamination.

To help answer these questions, let us consider an abstracted model (Fig. 4.5) by taking into account three major mechanisms that would affect the surface
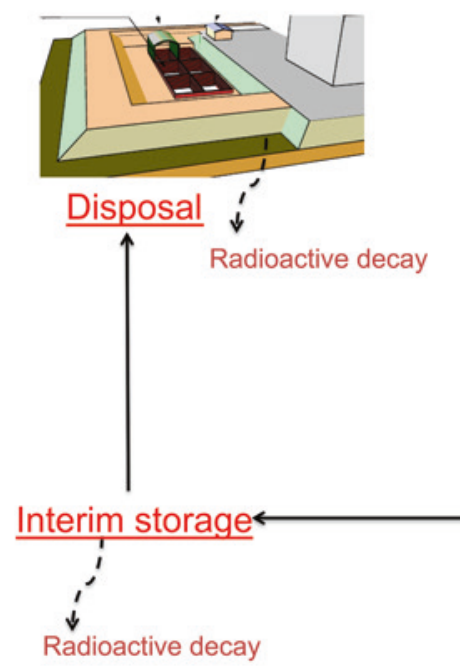

$\mathrm{A} \tau \tau=0, \beta\left(\mathrm{kBq} / \mathrm{m}^{2}\right)$

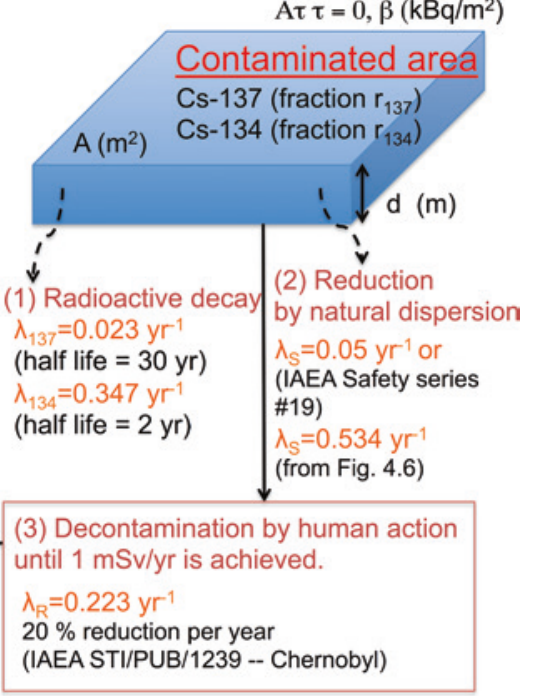

Fig. 4.5 Model for decontamination and waste management 
radioactivity concentration: (1) spontaneous radioactive decay, (2) natural dispersion, and (3) artificial decontamination actions, i.e., decontamination by human action. See Appendix for mathematical formulations.

\subsubsection{Mechanisms Considered in the Model}

\subsubsection{Radioactive Decay}

The first mechanism, spontaneous radioactive decay, is purely a physical process and one that is well understood. Nuclei of Cs-134 and Cs-137 decay with halflives of 2 years and 30 years, respectively, to Ba-134 and Ba-137. Because these barium isotopes are stable (i.e., not radioactive), it means that there is always some lessening of radioactivity occurring through this physical process.

\subsubsection{Natural Dispersion}

The second mechanism, natural dispersion, refers to the fact that cesium isotopes can move through the natural environment as a result of rainfall, wind, and the flow of water in surface and subsurface regions. To understand this mechanism, we need to know about the behavior of cesium in the environment, ranging from microscopic levels (such as the interaction of cesium with soil particles and microorganisms) to macroscopic levels (such as transport of cesium by groundwater, rivers, and off-shore ocean currents). The behavior of cesium in the environment is highly site-specific, heterogeneous at different scales, and evolves over time. Despite such complexity, the IAEA recommends a provisional value of 0.05 year $^{-1}$ [3] for the rate constant of this process. This value asserts that the radioactivity observed at a location of interest will be halved every 15 years, if only natural dispersion mechanisms are in play.

Recent measurements have revealed that natural dispersion mechanisms in Fukushima could be faster than the rate of 0.05 year $^{-1}$ IAEA recommends. Figure 4.6 indicates that the dose rates at various locations measured in December 2011 were about $70 \%$ of those measured in June 2011. In other words, during this 6-month period, radioactivity decreased by about $30 \%$ through spontaneous radioactive decay and natural dispersion. Note that no artificial decontamination activities were done during that period. With this data, the rate of natural dispersion is calculated to be 0.534 year $^{-1}$, which is about 10 times greater than the IAEA-recommended value. We consider two cases in the following analysis: fast $\left(0.534\right.$ year $\left.^{-1}\right)$ and slow $\left(0.05\right.$ year $\left.^{-1}\right)$ natural dispersion.

\subsubsection{Artificial Decontamination}

As for the third mechanism, artificial decontamination, the IAEA recommends a value of 0.223 year $^{-1}$ [7], based on its observations of decontamination done at Chernobyl. This value means that every year, $20 \%$ of the remaining radioactivity 
Fig. 4.6 Correlation between 2011/06 data and 2011/12 data for the air dose rate at various locations [6]

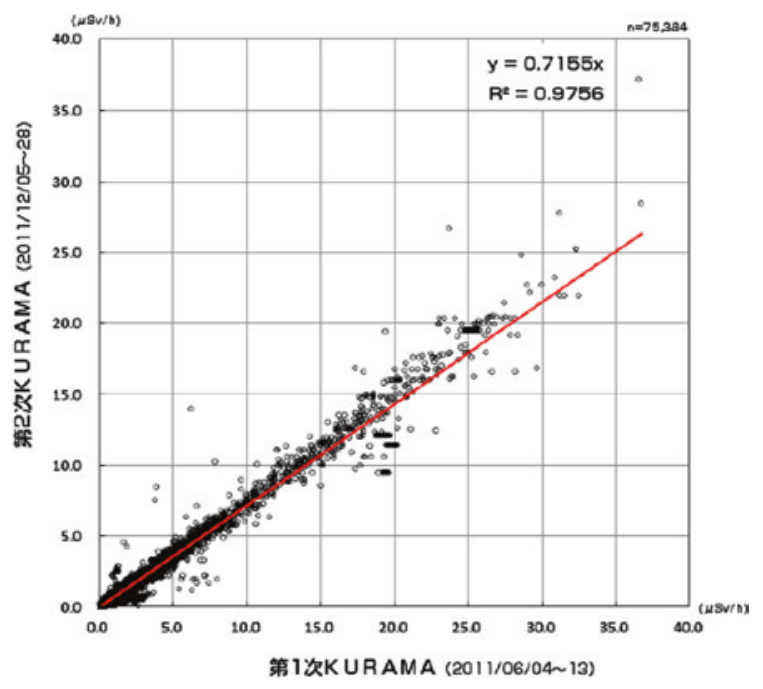

is removed from that location. Taking into account the second guideline defined by the law, we assume in the present modeling that artificial decontamination will continue until the annual dose of the area has become $1 \mathrm{mSv} / \mathrm{year}$ or lower. We consider two cases in the following analysis: with or without decontamination, for which the values of the rate constant are assumed to be 0.223 year $^{-1}$ or zero, respectively. As discussed below, the rate constant of artificial decontamination also varies significantly from place to place, because of different contamination conditions and, consequently, different techniques applied.

\subsubsection{Results}

Figure 4.7 and Table 4.1 show the results of numerical evaluation for four cases as combinations of with or without artificial decontamination and slow or fast natural dispersion. The chart at the left in Fig. 4.7 shows the results for the case with no artificial decontamination. Radioactivity in the environment decreases by the first and second mechanisms described above. Note that in this case, no waste is generated. The chart at the right shows the results for the case with artificial decontamination, which generates waste.

Two questions are addressed in relation to the two goals defined in the law: (1) Can the annual dose be made smaller than $20 \mathrm{mSv} / \mathrm{year}$ within 2 years? and (2) How long will it take for annual doses to become $1 \mathrm{mSv} /$ year or lower at any location?

Can the annual dose be made smaller than $20 \mathrm{mSv} / \mathrm{year}$ within 2 years? It should be noted that the dose rate exceeds $20 \mathrm{mSv} / \mathrm{year}$ if the initial contamination was $1,000 \mathrm{kBq} / \mathrm{m} 2$ or higher. Table 4.1 indicates that for the area with $1,000-3,000 \mathrm{kBq} / \mathrm{m} 2$ contamination, the dose rate would become below $20 \mathrm{mSv} /$ year within at most 2.52 years. For the area with $>3,000 \mathrm{kBq} / \mathrm{m} 2$, the time for 
the dose to become below $20 \mathrm{mSv} / \mathrm{year}$ is longer than that, but artificial decontamination can effectively shorten the time, particularly if the natural dispersion is slow (0.05 year-1). The results of actual measurement shown in Fig. 4.8 are consistent with this observation. In Fig. 4.8, it is observed that the dose rate comparison between September 18, 2011 (Fig. 4.8a) and September 28, 2013 (Fig. 4.8b) shows that the yellow zone, which corresponds to $1,000-3,000 \mathrm{kBq} /$ $\mathrm{m} 2$ initial contamination, actually decreased to below $20 \mathrm{mSv} / \mathrm{year}$, as indicated by the arrow in the figure. Similarly, the red zone shrank while the orange zone increased.
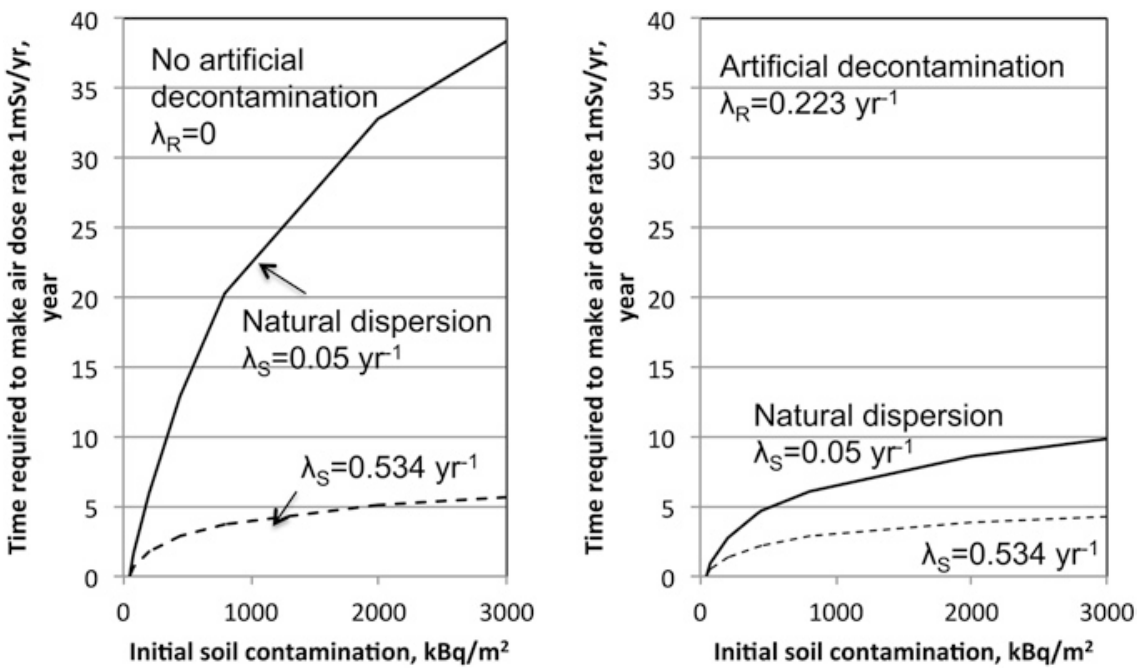

Fig. 4.7 Time required to make the air dose rate $1 \mathrm{mSv} / \mathrm{year}$ or lower as a function of initial surface soil contamination with (right) or without (left) artificial decontamination for the natural dispersion rate of 0.05 year $^{-1}$ (IAEA recommended) or 0.534 year $^{-1}$ (from Fig. 4.6)

Table 4.1 Effects of decontamination and natural dispersion

\begin{tabular}{l|l|l|l|l|l|l|l|l}
\hline \multirow{2}{*}{$\begin{array}{l}\text { Initial contamination, } \\
\beta\end{array}$} & \multicolumn{3}{l}{ Years to reach 20 mSv/year } & \multicolumn{3}{l}{ Years to reach 1 mSv/year } \\
\cline { 2 - 10 } & \multicolumn{2}{l}{$\begin{array}{l}\text { No decontami- } \\
\text { nation }\end{array}$} & $\begin{array}{l}\text { With decon- } \\
\text { tamination }\end{array}$ & \multicolumn{2}{l}{$\begin{array}{l}\text { No decontami- } \\
\text { nation }\end{array}$} & \multicolumn{2}{l}{$\begin{array}{l}\text { With decon- } \\
\text { tamination }\end{array}$} \\
\cline { 2 - 10 } & Fast & Slow & Fast & Slow & Fast & Slow & Fast & Slow \\
\hline$>3,000$ & $>1.43$ & $>4.32$ & $>1.10$ & $>2.19$ & $>5.67$ & $>38.4$ & $>4.25$ & $>9.83$ \\
\hline $1,000-3,000$ & 0.90 & 2.52 & 0.70 & 1.36 & 5.06 & 32.8 & 3.81 & 8.62 \\
\hline $600-1,000$ & - & - & - & - & 3.72 & 20.3 & 2.83 & 6.08 \\
\hline $300-600$ & - & - & - & - & 2.91 & 13.0 & 2.23 & 4.64 \\
\hline $100-300$ & - & - & - & - & 1.81 & 5.90 & 1.40 & 2.80 \\
\hline $60-100$ & - & - & - & - & 0.61 & 1.66 & 0.48 & 0.92 \\
\hline
\end{tabular}

fast natural dispersion rate $=0.534$ year $^{-1}$; slow 0.05 year $^{-1}$; - air dose rates always below $20 \mathrm{mSv} / \mathrm{year}$ 
(a)

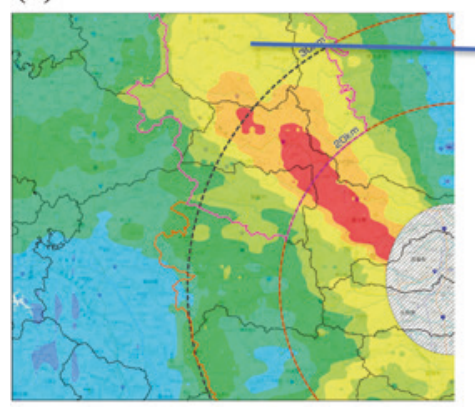

(b)

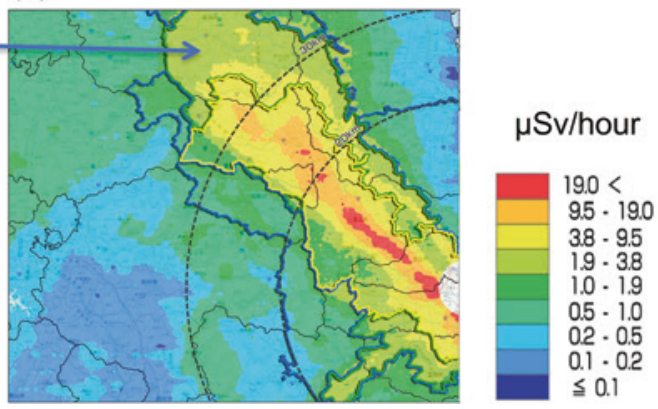

Fig. 4.8 Air dose rates ( $\mu \mathrm{Sv} / \mathrm{h})$ [8] a September 18, 2011 and b September 28, 2013

If the natural dispersion is actually fast, as observed in Fig. 4.7, effects of artificial decontamination on shortening the time to lower the dose rate below $20 \mathrm{mSv} / \mathrm{year}$ are limited; only a fraction of a year shortening is observed with the fast dispersion assumption. Because the natural dispersion processes occur heterogeneously in the environment, this observation indicates that artificial decontamination should be applied only in such areas where natural dispersion occurs slowly for the purpose of minimizing waste generation by decontamination.

How long will it take for annual doses to become $1 \mathrm{mSv} / \mathrm{year}$ or lower at any location? For the area with the initial contamination $<100 \mathrm{kBq} / \mathrm{m}^{2}$, in any conditions of natural dispersion, within at most 1.66 years the dose rate becomes below $1 \mathrm{mSv} / \mathrm{year}$. This time would not be significantly reduced by artificial decontamination. Thus, it makes no sense to apply artificial decontamination to areas with this low level of contamination. Not engaging in artificial decontamination also helps avoid waste generation. Between 100 and $1,000 \mathrm{kBq} / \mathrm{m}^{2}$, if the natural dispersion is observed to be fast, then artificial decontamination should not be applied because the time for the dose rate to become below $1 \mathrm{mSv} /$ year would not shorten significantly. However, if the natural dispersion is observed to be slow, artificial decontamination should be applied. Thus, similar to the observation for Question (1), it is crucial to identify regions where natural dispersion occurs slowly.

\subsection{Waste Generation by Decontamination}

\subsubsection{Model and Data}

As Fig. 4.5 shows, artificial decontamination generates waste materials containing radioactive cesium. From the observation in the previous section, we consider that artificial decontamination should be applied only in the region with the initial contamination of $300 \mathrm{kBq} / \mathrm{m}^{2}$ or greater. The area roughly corresponds to that 
shown in the expanded map in Fig. 4.3. In Table 4.2, the area for each contamination level is shown in the second column from the left. The total area subject to artificial decontamination is approximately $1,500 \mathrm{~km}^{2}$.

According to in-situ measurements for soil contamination [9], cesium has migrated into the soil to a depth of about $5 \mathrm{~cm}$. Assuming that the contaminated materials are removed from the area to a depth of $5 \mathrm{~cm}$, we can estimate the volume and mass of the radioactive waste to be generated by artificial decontamination activities (see Appendix for mathematical formulation).

\subsubsection{Results}

The third and fourth columns of Table 4.2 show results of the waste volume estimate for the cases of fast and slow natural dispersion by the model shown in the Appendix. Depending on the speed of natural dispersion, 16 or 24 million $\mathrm{m}^{3}$ of waste will be generated from decontamination for regions with $1,000 \mathrm{kBq} / \mathrm{m}^{2}$ or greater (the yellow and red regions in Fig. 4.3), respectively. But if artificial decontamination is applied to regions with lower contamination levels, the total volume of radioactive waste generated could be as large as 37 or 58 million cubic meters, respectively. The total volume of waste and, as discussed below, the cost are dependent on how decontamination is applied in the two low-contamination regions.

Radioactive waste from artificial decontamination will be characterized by huge volumes of low and heterogeneous radioactivity concentrations. Average concentrations of radioactivity that would be included in the waste from artificial decontamination are shown in Fig. 4.9. Those wastes have similar levels of radioactivity concentrations to those generated from hospitals, research laboratories, and nuclear-facility decommissioning, which are categorized as "very low-level waste (VLLW)" in Japanese regulations (Chap. 15). The results of previous studies [10] on cost estimates for disposal of Very Low Level Waste indicate that the least expensive option, called trench disposal, was estimated to be $650,000 \mathrm{yen} / \mathrm{m}^{3}$, or $\$ 25$ per gallon of waste.

Table 4.2 Evaluation of volume and cost of disposal for radioactive waste arising from decontamination

\begin{tabular}{|c|c|c|c|c|c|}
\hline \multirow{2}{*}{$\begin{array}{l}\text { Initial soil } \\
\text { contamination, } \\
\beta\left(\mathrm{kBq} / \mathrm{m}^{2}\right)\end{array}$} & \multirow{2}{*}{$\begin{array}{l}\text { Area, A, } \\
\text { included } \\
\text { in Fig. } 4.3 \\
\left(\mathrm{~km}^{2}\right)\end{array}$} & \multicolumn{2}{|c|}{ Waste volume (million $\mathrm{m}^{3}$ ) } & \multicolumn{2}{|c|}{ Estimated cost (trillion yen) } \\
\hline & & $\begin{array}{l}\text { Fast } \\
\text { dispersion }\end{array}$ & \begin{tabular}{|l} 
Slow \\
dispersion
\end{tabular} & $\begin{array}{l}\text { Fast } \\
\text { dispersion }\end{array}$ & \begin{tabular}{|l|} 
Slow \\
dispersion
\end{tabular} \\
\hline$>3,000$ & 183 & 5.60 & 8.13 & 3.64 & 5.28 \\
\hline $1,000-3,000$ & 368 & 10.5 & 15.7 & 6.83 & 10.2 \\
\hline Subtotal & 551 & 16.1 & 23.8 & 10.5 & 15.5 \\
\hline $600-1,000$ & 282 & 6.60 & 10.5 & 4.29 & 6.83 \\
\hline $300-600$ & 721 & 14.1 & 23.2 & 9.17 & 15.1 \\
\hline Subtotal & 1,003 & 20.7 & 33.7 & 13.5 & 21.9 \\
\hline Total & 1,554 & 36.8 & 57.5 & 23.9 & 37.4 \\
\hline
\end{tabular}




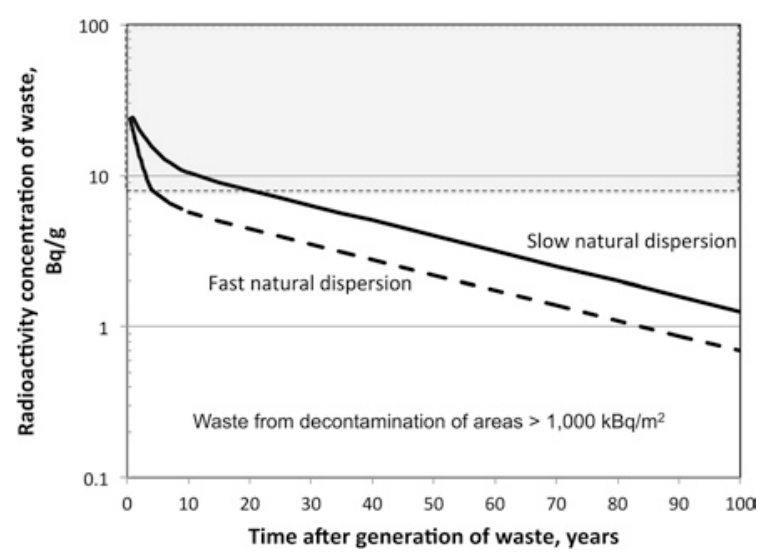

Fig. 4.9 Average radioactivity concentration in $\mathrm{Bq} / \mathrm{g}$ of waste generated from decontamination of areas with initial contamination of $>1,000 \mathrm{kBq} / \mathrm{m}^{2}$ for fast or slow natural dispersion. Average density of $1,600 \mathrm{~kg} / \mathrm{m}^{3}$ is assumed. For waste with concentrations in the hatched region, disposal in controlled landfill sites is required by Japanese law (see Chap. 15)

The two rightmost columns in Table 4.2 show the estimated cost. Depending on the area targeted for decontamination, the cost of decontamination varies greatly. Even if decontamination is limited to highly contaminated areas where the dose rate is above $20 \mathrm{mSv} / \mathrm{year}$, the cost is likely to be on the order of ten trillion yen.

\subsection{Concluding Remarks: Conflicting Values and Motives}

This result from the waste generation analysis indicates the importance of waste volume reduction, for which basically two approaches can be considered. The first is strategic selection of areas for decontamination. Decontamination has been found to effectively contribute to reduction of the air dose rate if it is applied in areas where natural dispersion is slow. The second is development of volume reduction technologies, which include incineration, physical and chemical partitioning, and compaction. Both approaches should be applied in a concerted manner.

Thanks to fast natural dispersion processes as observed in Fig. 4.6, the air dose rate due to surface soil contamination in the environment has been decreasing more rapidly than expected. To take advantage of this natural process, it is crucially important to strategically select areas for artificial decontamination, i.e., where natural dispersion occurs more slowly than in other areas, so that generation of unnecessary waste can be effectively avoided. This will accelerate decontamination, and consequently help return evacuees to their homes.

Unfortunately, sufficient information and knowledge that enable strategic prioritization of areas for decontamination are not currently available. From the analysis shown in this chapter, these are primarily related to in-depth understanding 
about natural dispersion phenomena represented by $\lambda_{S}$, including (1) the interaction of radionuclides with materials in the natural environment, (2) the transport and dispersion of radionuclides in the natural environment, and (3) the measurement of radiation and radionuclides in the environment. Furthermore, the value of the rate $\lambda_{\mathrm{R}}$ of artificial decontamination for the model used in this chapter should have been obtained through actual decontamination work. In the past 3 years, although decontamination has been carried out in more than 100 local municipalities, data, experience, and knowledge have not been made available in the public domain in forms that can be utilized for further analyses and feedback.

However, even with perfect knowledge and information about natural dispersion phenomena and decontamination effects, strategic prioritization cannot be actually implemented unless a broad range of stakeholders agrees on prioritization. On the contrary, what has actually occurred in the past 3 years indicates that the issue of decontamination has sensitized differences among people about what needs to be achieved by decontamination, resulting in belated decision making on various important matters, which has led to greater and prolonged hardship for the evacuees.

We observe a vicious cycle consisting of a lack of integrated scientific knowledge base about environmental contamination and deterioration in trust among stakeholders in society. For trust building, a goal that can be shared by various stakeholders needs to be set, and exactly for that purpose, a solid scientific basis is crucially important. At the same time, without understanding the goal, the right set of scientific bases cannot be defined.

To halt this vicious cycle, we need to establish a fundamental scientific basis, both natural and social, for enabling in-depth analysis about what has been the most crucial damage resulting from the accident and why that occurred, and how radiological risk can or should be compared with other risks in society. Coupled with such scientific efforts, advanced concepts and technologies should be developed and implemented to facilitate decision making by a broad range of stakeholders, which would significantly enhance the resilience of society (see more discussion in Chap. 24).

Acknowledgments The author would like to express his deepest gratitude to Dr. Shinichi Nakayama of Japan Atomic Energy Agency for his help in arranging the trip to Fukushima in September 2012, as well as his insightful comments to this chapter. The author also would like to extend his special thanks to Professor Gayle K. Sato of Meiji University for her excellent comments and advice to improve readability of this chapter. Needless to say, any inaccuracy or lack of readability in this chapter is laid to the author's responsibilities.

\section{Appendix: Mathematical Formulations}

\section{For Decontamination}

\section{During Decontamination $\left(0 \leq t<t_{1}\right)$}

For the radioactivity $M_{i}[\mathrm{kBq}]$ of nuclide $i$ in contaminated area of $A\left[\mathrm{~m}^{2}\right]$ : 


$$
\begin{aligned}
& \frac{d M_{i}}{d t}=-\left(\lambda_{i}+\lambda_{R}+\lambda_{S}\right) M_{i}, \quad 0<t \leq t_{1}, \\
& \text { subject to } M_{i}(0)=M_{i}^{o} \quad i=134,137
\end{aligned}
$$

where $M_{i}^{0}=\beta A r_{i}[\mathrm{kBq}]$, where $r_{137}+r_{134}=1$. The quantity $r_{i}$ is the mass fraction of nuclide $i$ included in the contamination. The quantity $\beta$ is the initial soil contamination $\left[\mathrm{kBq} / \mathrm{m}^{2}\right]$ for the area of interest. The constants $\lambda_{i}, \lambda_{R}$, and $\lambda_{S}$ are the radioactive decay constant, the rate of artificial decontamination, and the rate of natural dispersion, respectively. The time $t_{1}$ is the time when the air dose of the area becomes $1 \mathrm{mSv} /$ year and the decontamination actions are stopped.

The solution for this is written as:

$$
M_{i}(t)=M_{i}^{o} \exp \left(-\lambda_{i}^{\prime} t\right), \quad 0 \leq t \leq t_{1}, \quad \text { where } \quad \lambda_{i}^{\prime}=\lambda_{i}+\lambda_{R}+\lambda_{S}
$$

With the dose conversion factor $C_{i}\left[(\mu \mathrm{Sv} / \mathrm{h}) /\left(\mathrm{kBq} / \mathrm{m}^{2}\right)\right]$, the air dose rate is written as $C_{i} M_{i} / A[\mu \mathrm{Sv} / \mathrm{h}]$. Assume the person stays outside for $8 \mathrm{~h}$ a day and inside $16 \mathrm{~h}$ a day, and $40 \%$ dose while inside, the annual dose is calculated to be $F C_{i} M_{i}$ $(t) / A[\mathrm{mSv} /$ year $]$, where $F=(8 \mathrm{~h}+16 \times 0.4 \mathrm{~h}) \times 365 / 1,000=5.26[(\mathrm{mSv} / \mu \mathrm{Sv})$. (hour/year)]. The annual dose $S_{i}(t)$ [mSv/year] due to nuclide $i$ in this area is formulated as:

$$
\begin{aligned}
S_{i}(t) & =F C_{i} M_{i}(t) /_{A}=\left(F C_{i} M_{i}^{o} / A\right) \exp \left(-\lambda_{i}^{\prime} t\right) \\
& =\left(F C_{i} \beta r_{i}\right) \exp \left(-\lambda_{i}^{\prime} t\right)[\mathrm{mSv} / \text { year }], \quad 0 \leq t \leq t_{1} .
\end{aligned}
$$

The cumulative dose due to nuclide $i$ is obtained by integrating this with respect to time as:

$$
\Sigma_{i}(t)=\left(F C_{i} \beta r_{i} / \lambda_{i}^{\prime}\right)\left[1-\exp \left(-\lambda_{i}^{\prime} t\right)\right][\mathrm{mSv}], \quad 0 \leq t \leq t_{1}
$$

\section{Termination of Decontamination $\left(t=t_{1}\right)$}

The time $t_{1}$ for terminating decontamination is when the total air dose rate becomes less than $1 \mathrm{mSv} / \mathrm{year}$. The time $t_{1}$ can be obtained by solving numerically

$$
S_{137}\left(t_{1}\right)+S_{134}\left(t_{1}\right)=1[\mathrm{mSv} / \text { year }] \text {. }
$$

If the dose rate is already less than $1 \mathrm{mSv} /$ year at $t=0$, then no decontamination is necessary. For that, the initial soil contamination level is obtained as

$$
S_{137}(0)+S_{134}(0) \leq 1[\mathrm{mSv} / \text { year }] \text {. }
$$

$$
\text { Or } \quad \beta \leq \beta_{\text {threshold }}=\frac{1}{F\left(C_{137} r_{137}+C_{134} r_{134}\right)}\left[\mathrm{kBq} / \mathrm{m}^{2}\right] .
$$

With the values of $F=5.26, C_{137}=2.1 \mathrm{E}-3, C_{134}=5.6 \mathrm{E}-3, r_{137}=r_{134}=0.5$, $\beta_{\text {threshold }}=49.4 \mathrm{kBq} / \mathrm{m}^{2}$. 


\section{After Termination of Decontamination $\left(t>t_{1}\right)$}

For the radioactivity $M_{i}[\mathrm{kBq}]$ of nuclide $i$ in contaminated area of $A\left[\mathrm{~m}^{2}\right]$ :

$$
\begin{aligned}
& \frac{d M_{i}}{d t}=-\left(\lambda_{i}+\lambda_{S}\right) M_{i}, \quad t>t_{1}, \\
& \text { subject to } M_{i}\left(t_{1}\right)=M_{i}^{o} \exp \left(-\lambda_{i}^{\prime} t_{1}\right), \quad i=134,137
\end{aligned}
$$

The solution for this is written as:

$$
M_{i}(t)=M_{i}\left(t_{1}\right) \exp \left(-\left(\lambda_{i}+\lambda_{S}\right)\left(t-t_{1}\right)\right), \quad t \geq t_{1} .
$$

The annual dose $S_{i}(t)$ [mSv/year] due to nuclide $i$ in this area is formulated as:

$$
S_{i}(t)=S_{i}\left(t_{1}\right) \exp \left(-\left(\lambda_{i}+\lambda_{S}\right)\left(t-t_{1}\right)\right)[\mathrm{mSv} / \text { year }], \quad t \geq t_{1} .
$$

The cumulative dose due to nuclide $i$ is obtained by integrating this with respect to time as:

$$
\Sigma_{i}(t)=\Sigma_{i}\left(t_{1}\right)+\frac{S_{i}\left(t_{1}\right)}{\lambda_{i}+\lambda_{S}}\left[1-\exp \left(-\left(\lambda_{i}+\lambda_{S}\right)\left(t-t_{1}\right)\right)\right][\mathrm{mSv}], \quad t \geq t_{1} .
$$

\section{For Waste Characterization}

\section{During Decontamination $\left(\mathbf{0} \leq \mathbf{t}<\mathbf{t}_{1}\right)$}

For the radioactivity $W_{i}[\mathrm{kBq}]$ of nuclide $i$ in waste:

$$
\begin{aligned}
& \frac{d W_{i}}{d t}=\lambda_{R} M_{i}-\lambda_{i} W_{i}, \quad 0<t \leq t_{1}, \\
& \text { subject to } W_{i}(0)=0, \quad i=134,137
\end{aligned}
$$

where

$$
\begin{aligned}
M_{i}(t) & =M_{i}^{o} \exp \left(-\lambda_{i}^{\prime} t\right), \quad 0 \leq t \leq t_{i}, \\
\lambda_{i}^{\prime} & =\lambda_{i}+\lambda_{R}+\lambda_{S}, \\
M_{i}^{o} & =\beta A r_{i}[\mathrm{kBq}], \quad \text { where } r_{137}+r_{134}=1
\end{aligned}
$$

The solution is

$$
W_{i}(t)=M_{i}^{o} \frac{\lambda_{R}}{\lambda_{R}+\lambda_{S}} \exp \left(-\lambda_{i} t\right)\left\{1-\exp \left(-\left(\lambda_{R}+\lambda_{S}\right) t\right)\right\}[\mathrm{kBq}], \quad 0 \leq t \leq t_{1} .
$$

Assume that radionuclides are included in the waste materials removed from the area. The cumulative volume, $W_{V}(t)\left[\mathrm{m}^{3}\right]$, of the waste materials is formulated as:

$$
W_{V}(t)=A d\left\{1-\exp \left(-\lambda_{R} t\right)\right\}\left[\mathrm{m}^{3}\right], \quad 0 \leq t \leq t_{1} .
$$


The cumulative mass, $W_{M}(t)[\mathrm{kg}]$, of the waste materials is formulated as:

$$
W_{M}(t)=\operatorname{Ad} \rho\left\{1-\exp \left(-\lambda_{R} t\right)\right\}[\mathrm{kg}], \quad 0 \leq t \leq t_{1} .
$$

The average radioactivity concentration of the waste is

$$
\frac{W_{137}(t)+W_{134}(t)}{W_{M}(t)}[\mathrm{Bq} / \mathrm{g}], \quad 0 \leq t \leq t_{1} .
$$

\section{After Termination of Decontamination $\left(t>t_{1}\right)$}

For the radioactivity $W_{i}[\mathrm{kBq}]$ of nuclide $i$ in waste:

$$
\begin{aligned}
\frac{d W_{i}}{d t} & =-\lambda_{i} W_{i}, \quad t>t_{1} \\
\text { subject to } W_{i}\left(t_{1}\right) & =M_{i}^{o} \frac{\lambda_{R}}{\lambda_{R}+\lambda_{S}} \exp \left(-\lambda_{i} t_{1}\right)\left\{1-\exp \left(-\left(\lambda_{R}+\lambda_{S}\right) t_{1}\right)\right\} \\
i & =134,137
\end{aligned}
$$

The solution is

$$
W_{i}(t)=W_{i}\left(t_{1}\right) \exp \left(-\lambda_{1}\left(t-t_{1}\right)\right), \quad t \geq t_{1}
$$

After $t_{1}$, no more waste is generated. Thus, the cumulative volume, $W_{V}(t)\left[\mathrm{m}^{3}\right]$, and the cumulative mass, $W_{M}(t)[\mathrm{kg}]$, of the waste materials are constant at the value of $t_{1}$ :

$$
\begin{gathered}
W_{V}(t)=A d\left\{1-\exp \left(-\lambda_{R} t_{1}\right)\right\}\left[\mathrm{m}^{3}\right], \quad t \geq t_{1}, \\
W_{M}(t)=A d \rho\left\{1-\exp \left(-\lambda_{R} t_{1}\right)\right\}[\mathrm{kg}], \quad t \geq t_{1} .
\end{gathered}
$$

The average radioactivity concentration of the waste is:

$$
\frac{W_{137}(t)+W_{134}(t)}{W_{M}\left(t_{1}\right)}[\mathrm{Bq} / g], \quad t \geq t_{1} .
$$

Open Access This chapter is distributed under the terms of the Creative Commons Attribution Noncommercial License, which permits any noncommercial use, distribution, and reproduction in any medium, provided the original author(s) and source are credited.

\section{References}

1. An, K (1996) Kokoro no kizu wo iyasuto iu koto: Kobe-365 nichi (To heal mental trauma: Kobe 365 days) (in Japanese). ISBN-10: 487893249X. Sakuhinsha, Tokyo

2. Ministry of Education, Culture, Sorts, Science and Technology (MEXT), Japanese Government (2011) Results of airborne monitoring by MEXT. Available at: http:// radioactivity.nsr.go.jp/ja/contents/5000/4896/24/1910_092917_1.pdf (in Japanese). Accessed 10 July 2014 
3. International Atomic Energy Agency (2001) Generic models for use in assessing the impact of discharges of radioactive substances to the environment. Safety Reports Series 19, STI/ PUB/10103 (ISBN 92-0-100501-6). IAEA, Vienna

4. Komori M, Shozugawa K, Nogawa N, Matsuo M (2013) Evaluation of radioactive contamination caused by each plant of Fukushima Daiichi Nuclear Power Station using ${ }^{134} \mathrm{Cs} /{ }^{137} \mathrm{Cs}$ activity ratio as an index. Bunseki Kagaku 62(6): 475-483 (in Japanese)

5. Act on Special Measures concerning the Handling of Environment Pollution by Radioactive Materials Discharged by the Nuclear Power Station Accident Associated with the Tohoku District - Off the Pacific Ocean Earthquake that Occurred on March 11, 2011 enacted on August 30, 2011 by the National Diet of Japan. Available at: http://law.e-gov.go.jp/htmldata/ H23/H23HO110.html (in Japanese).

6. Ministry of Education Culture, Sports, Science and Technology (MEXT), Japanese Government (2012) Results of continuous measurement of air dose rates by moving automobiles conducted by MEXT as of December 2012. Available at: http://radioactivity.nsr.go.jp/ja/ contents/6000/5052/24/338_0321_18.pdf (in Japanese)

7. International Atomic Energy Agency (2006) Environmental consequences of the Chernobyl accident and their remediation: Twenty years of experience. Report of the UN Chernobyl Forum Expert Group "Environment", Radiological Assessment Reports Series 8, STI/ PUB/1239 (ISBN 92-0-114705-8)

8. Japan Map Center (2011) Extension site of distribution map of radiation dose, etc. Available at: http://ramap.jmc.or.jp/map/eng/

9. Shiozawa S (2013) Vertical migration of radiocesium fallout in soil in Fukushima. In: Nakanishi TM, Tanoi K (eds) Agricultural implications of the Fukushima nuclear accident. Springer Japan. ISBN: 978-4-431-54327-5 (Print) 978-4-431-54328-2 (Online)

10. Ministry of Education, Culture, Sports, Science and Technology (MEXT), Japanese Government (21 July 2006) Efforts toward realization of disposal of RI and laboratory wastes (Shallow Land Burial) Available at: http://www.mext.go.jp/b_menu/shingi/gijyutu/gijyutu2/t oushin/06110922/001.htm (in Japanese) 